[Vol. 129:856

\title{
AIRLINE MERGERS IN THE NEW REGULATORY ENVIRONMENT
}

\author{
Almarin Phillips †
}

The architects of airline deregulation were not wrong in pressing their cause. The old system had developed notorious ineffciencies. $^{1}$ Regulation had for years effectively prevented the entry of new carriers offering low fare, "no frills" service on domestic routes. In the later years, regulatory policy favored multiple carrier operations on high traffic density routes, yet price competition among the certificated domestic carriers was heavily circumscribed. Consequently, rivalry among carriers often tended to be in the form of nonprice competition-flight frequency, food and beverage service, flight equipment, ground services, and advertising-which tended to increase operating costs. ${ }^{2}$ The local service carriers were encouraged to grow, but largely as feeders for, or complements to, the trunk carriers. ${ }^{3}$ The Civil Aeronautics Board (CAB) encouraged cost-increasing, nonprice competition-thus necessitating approval of fare increases justified only by the rising costs for which its own policies had been responsible.

The proponents of deregulation, however, were hopelessly naive in their often implicit, always sanguine evaluations of the structural consequences of deregulation. Armed with the economic theory of competition, with evidence suggesting an absence of significant economies of scale, with faith in the efficacy of free entry, and, after the mid-1970s, perhaps, with a contagious fervor to deregulate something, they assumed that there would not be a need for significant structural readjustments in the new competitive

$\uparrow$ Professor of Economics, Law and Public Policy, University of Pennsylvania. B.S. 1948, M.A. 1949, University of Pennsylvania; Ph.D. 1953, Harvard University.

1 See generally H.R. REP. No. 1211, 95th Cong., 2d Sess. 1-79, reprinted in [1978] U.S. COde Cong. \& Ad. News 3737, 3737-73; S. Rep. No. 621, 95th Cong., 2d Sess. 1-228 (1978); Stucomm. ON Admanistaative Practice and Procedore, Senate Comm. on the Judiciary, 94tri Cong., Ist Sess., Civil Aeronautics Board Practices and Procedures 1-255 (Comm. Print 1975).

2 See generally W. JoRdan, AIRtINE Regulation In AMERrca (1970) (comparing the effect of Civil Aeronautics Board (CAB) price regulation on service rivalry and quality with the service quality of non-price-regulated intrastate California carriers).

3 There are presently 11 domestic trunk carriers, 3 air cargo carriers, and 43 local service carriers. For a more comprehensive description of the relationship between trunk lines and local service carriers, see Comment, Competitive Policy in Airline Deregulation, 28 AM. U. L. REv. 537, 543-44 (1979). 
environment. ${ }^{4}$ More specifically, they either failed to consider the possibility of, or assumed that there would not be, significant reduction in the number of carriers concomitant with deregulation. The vision of the deregulated airline industry as effectively competitive suggested that merger policies developed under the antitrust laws would suffice for whatever mergers and acquisitions might transpire. ${ }^{5}$

In this the proponents of deregulation were wrong. The traditional "structure-conduct-performance" method of analysis used by economists ${ }^{6}$ and by the courts in evaluating the competitive impacts of mergers is of doubtful relevance when a move from a heavily regulated to an essentially deregulated environment is underway. Even if it is true that a highly concentrated market structure tends to produce poor economic performance under relatively static market conditions, this truth obscures the more important relationships between structure and performance in a dynamic setting. ${ }^{7}$ Deregulation creates such a setting. Thus, traditional views

4 See, e.g., R. Caves, Ain Transport and Its Regulators (1962); F. Gill \& G. Bates, Amulne Competrtion: A Study of the Effects of Competriton on the Quajtiy and Price of Amulne Service and the Self-Sufficiency of the United States Domestic Aurlines (1949); W. Fruman, The Fight for Competitive Advantage: A StUdy of the United States Domestic Trunk AIR Carruers (1972); W. Jordan, supta note 2; Bluestone, The Problem of Competition Among Domestic Trunk Airlines-Part I, 20 J. Aln L. \& CoM. 379 (1953); Douglas \& Miller, The CAB's Domestic Passenger Fare Investigation, 5 BEL. J. Ecos. \& MGmT. Scr. 205 (1974); Eads, Competition in the Domestic Trunk Airline Industry: Too Much or Too Little?, in Promoting Competition IN Regulated Markets 13-54 (A. Phillips ed. 1975); Kahn, Deregulation Of Air Transport-Getting From Here To There, in Regulating Business: The Search for an Optimum (1978); White, Quality Variation When Prices are Regulated, 3 BexL J. Econ. \& MGMr. Scx. 425 (1972).

5 The House Conference Report contained the following language:

The foundation of the new airline legislation is that it is in the public interest to allow the airline industry to be governed by the forces of the marketplace. Consistent with that premise, mergers of air carriers should be governed by the same standards that are applied to mergers of other firms.

H.R. REp. No. 1779, 95th Cong., 2d Sess. 73, reprinted in [1978] U.S. Code Cong. \& AD. NEws 3789.

- For an explanation of the structure-conduct-performance approach to market

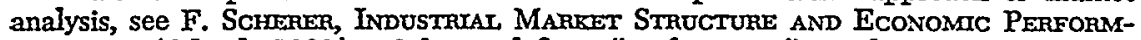
ANCE 3-6 (2d ed. 1980). Scherer defines "performance" as the extent to which goals such as productive and allocative efficiency, full employment, and overall social equity are met. Id. $3-4$. "Conduct" encompasses pricing, marketing, investment, advertising, research and development, and enforcement of legally conferred monopolies. Id. 4. "Structure" refers to a given market; the number of sellers and buyers, extent of vertical integration, barriers to entry, and so on. Id.

$\tau$ An explanation of the theories concerning the static consequences of concentration on performance, and a survey of empirical tests of their validity, are contained in F. SCHERER, supra note 6 , at ch. 9.

The dynamic aspects of competition are key components of "corporate strategy" concepts that have found a wide audience among business managers and executives. See, e.g., B. Henderson, Corporate Strategy 90, 170 (1979). 
relating structure, or changes in structure, to market performance do not apply. Deregulation raises more fundamental questions about how changes in conduct and performance affect market structure. Mergers and acquisitions were bound to occur because of the intensity of the new rivalry and the inevitable consequence that some of the carriers would do well and others, artificially bolstered by prior regulation, would fail. ${ }^{8}$

The Airline Deregulation Act of 1978, adopting antitrust's "structure-conduct-performance" approach to competition policy," largely ignores the near-inevitability that the rivalry engendered in unregulated markets will induce structural changes. One purpose of the Act is to make available "a variety of adequate, economic, efficient, and low-price services by air carriers." 11 This is to be accomplished by placing "maximum reliance on competitive market forces and on actual and potential competition." 12 To assure that competition works to produce the desired results, the CAB (and, subsequent to January 1, 1983, the Department of Justice) was mandated to prevent "anticompetitive practices in air transportation, and the avoidance of ... unreasonable industry concentration, excessive market domination, and monopoly power ... that would tend to allow one or more air carriers unreasonably to increase prices, reduce services, or exclude competition in air trans-

${ }^{8}$ Many domestic trunk airlines have in fact suffered severe drops in profit levels since deregulation. Blame for the situation has been placed on the $C A B$ as well as on rising fuel costs and the unfamiliar price rivalry. See Williams, Ailing Airlines Blame CAB, N.Y. Times, Feb. 22, 1980, at D1, col. 4. The particular problems of Braniff Airways have been charted in Holsendolph, Braniff Raising Fares 25\%, N.Y. Times, May 17, 1980, at 29, col. 6 and McInnis, Braniff Airways: Color It Red, N.Y. Times, May 18, 1980, at F9, col. 1.

9 Pub. L. No. 95-504, 92 Stat. 1705 (codified at 49 U.S.C. $\$ \$ 1301-1552$ (Supp. II 1978)).

10 Section 26 of the Airline Deregulation Act dictates that a merger not be approved if "the [Civil Aeronautics] Board finds that the transaction will not be consistent with the public interest" or

(A) if it would result in a monopoly or would be in furtherance of any combination or conspiracy to monopolize or to attempt to monopolize the business of air transportation in any region of the United States; or

(B) the effect of which in any region of the United States may be substantially to lessen competition, or to tend to create a monopoly, or which in any other manner would be in restraint of trade, unless the Board finds that the anticompetitive effects of the proposed transaction are outweighed in the public interest by the probable effect of the transaction in meeting significant transportation conveniences and needs of the public, and unless it finds that such significant transportation conveniences and needs may not be satisfied by a reasonably available alternative having materially less anticompetitive effects.

49 U.S.C. $\$ \$ 1378(\mathrm{~b})(1)(\mathrm{A})-(\mathrm{B})$ (Supp. II 1978).

11 Id. $\$ 1302$ (a)(3) (Supp. II 1978).

12 Id. $\$ 1302(\mathrm{a})(4)$. 
portation." 13 That is, by preserving an "unconcentrated market," the Board would, by definition, protect the public interest in adequate and efficient air service.

The application of any "structure-conduct-performance" theory to airline mergers is questionable for two reasons. First, the domestic air carrier markets cannot be characterized, either before or after regulatory reform, as operating under conditions even closely approximating those of static, perfect competition. ${ }^{34}$ The carriers produce multiple and differentiated products for different customer classes travelling widely varying distances over different geographic areas. The costs and revenues of the carriers vary with the products produced, the network of cities served, the equipment used, flight frequencies, the quality of the service, and advertising and sales promotion activities. These complex cost and demand conditions require that the policy questions relating to industry structure, economies of scale, network economies, entry barriers, and actual and potential competition be addressed within the framework of a dynamic differentiated industry.

Second, the "structure-conduct-performance" theory and its use in assessing the competitive effects of current and prospective airline mergers rest on an inadequate assignment of causation in the deregulated environment. The traditional view has been that industry structure gives rise to specific types of conduct. ${ }^{16}$ In the deregulated airline industry, the exact opposite is true. The shift from a regulated to an unregulated setting obviously meant that the carriers, starting from a condition far from an equilibrium, would have to develop and employ new modes of conduct in response to new market conditions. These responses had of necessity to include new policies with respect to route structures, fare structures, service frequency, service quality, flight equipment, ground service and promotion. Given the initial disequilibrium and these responses, competition must be viewed not as a simple price-quantity equilibrating mechanism operating within a given market structure, but rather as a dynamic process that causes changes in structure. The analysis must therefore address the question of how the

$131 d . \$ 1302(\mathrm{a})(7)$.

14 For a discussion of the complexity of these issues in econometric terms, see G. Dougras \& J. MinLer, Economic Regulation of Domestic Am Transpont (1974) and N. Taneja, The Comamercial AurLine Industry 131-44 (1976). Competition in the industry is modeled in D. Wycroff \& D. Marster, TrE Domestic AmLine Industry lxix-lsxxiv (1977). See also F. Scherer, supra note 6 , at 385-86.

15 This is the classic theory of monopolistic and oligopolistic pricing. See, e.g., F. Scherer, supra note 6, at 151-68 (expressing, however, reservations about the effect of oligopolistic structure on pricing conduct and profit performance). 
actual and perceived changes in the performance of the carriers are likely to "feedback" to private decisions affecting the hitherto regulated and unregulated aspects of structure and conduct. ${ }^{16}$

Structure, conduct and performance are closely interrelated through time. Change in any one element continually induces change in the others. ${ }^{17}$ In this context, deregulation must be seen as a potential cause of structural change, including mergers. Application of current legal doctrine concerning mergers, without accommodation of particular aviation industry needs, and in a situation of great flux, may have particularly undesirable long term effects. ${ }^{18}$ Merger policy must thus be formulated only after careful examination of the effects of deregulation on structure and of the consequent structure on performance.

The next part of this Article discusses airline costs. Consideration is given to cost differences due to route structure, product differentiation, and scale of operations, with attention to differences between incremental costs and full average costs. Part II then turns to demand characteristics, with a discussion of elasticities, cross-elasticities and the demand aspects of quality variations and promotional activities. Differences in the "density" (quantity per unit of time) of demand are discussed. An analysis of entry and barriers to entry, which combines both cost and demand factors, follows in part III.

With cost, demand and entry elements developed, part IV turns to the reasons for and probable effects of mergers. Ghanges in efficiency as well as changes in the degree of monopoly power that may result from mergers of air carriers with varying cost and demand characteristics are addressed. The conclusion suggests a

16 The impact of dynamic change in the market on the pricing discipline is demonstrated in F. Scherer, supra note 6, at 205-12. See also A. Prmints, Market Structure, Organtzation, and Performance 175-76 (1962).

17 For somewhat more detailed views of the dynamic aspects of the aviation industry, see Phillips, Structure, Conduct and Performance-And Performance, Conduct and Structure, in Industrual Organization and Economic Development (J. Markham \& G. Papanek eds. 1970) and Phillips, Commentary, in Industratar Concentration: The New Learning 408-13 ( $\mathrm{H}$. Goldschmid, H. Mann \& J. Weston eds. 1974). For a similar market analysis in the context of technological change, see A. Phmlups, Technology and Market Sthucture: A Study of the AmRRAFT INDUSTRY (1971) and Nelson \& Winter, Forces Limiting and Generating Concentration under Schumpeterian Competition, 9 BELL. J. EcoN. 524 (1978).

18 This Article will not discuss CAB disposition of recent merger applications. Reviews of the cases can be found in Brodley, CAB Merger Policy Under Deregulation: Legal Standards and Economic Needs, - B.U. L. Rev. - (1981); Keyes, A Preliminary Appraisal of Merger Control under the Airline Deregulation Act of 1978, 46 J. ArR L. \& CoM. 71 (1980); and Simowitz, Mating Rights: Deregulation and Airline Mergets, in ABA-Section of Publtc Utiluty Law ANnual Report 43 (1980). 
new approach to review of proposed mergers. This approach eschews reliance on market concentration as the touchstone of the analysis. It thus accommodates the dynamic relations among structure, conduct, and performance in an environment in which fares, route structures, and entry are largely deregulated.

\section{Airline Operating Costs}

The proponents of deregulation minimized the importance of mergers among the carriers after deregulation because of a perceived lack of significant economies of scale. A number of independent studies had shown that once a carrier achieved a two to three percent share of total available domestic seat or ton miles, ${ }^{19}$ there were no further discernible decreases in average costs as the size of carriers increased. ${ }^{20}$ In fact, some of the larger carriers were reported to have higher costs than the smaller and medium sized ones. The absence of pronounced scale economies would mean that the minimum efficient size of a carrier is obstensibly small enough to permit as many as thirty to fifty carriers to operate simultaneously without losses in system efficiency.

There are several important limitations pertaining to these econometric results. First, the cost observations on which they are based were made prior to deregulation. At that time, route structures were essentially fixed. Cost variations among the carriers could arise from carrier decisions to change the available seat or ton miles, but the carriers were relatively powerless to alter official route assignments. The studies therefore overlook the potentially significant economies arising from rerouting flexibility at a carrier's initiative.

Second, the studies measure the output of the carriers in a single, homogeneous unit-seat miles or ton miles. They ignore

19 An "available seat mile" represents one seat, available for a revenue paying passenger, carried one mile. An "available ton mile" is defined analogously in terms of revenue tons (passenger and cargo weights combined). These are the most commonly used units for measuring the quantity of airline services supplied over a period of time. Because carrier costs are more directly related to the number of seats than to the number of passengers flown, "available seat miles" is a more useful measure in airline cost studies than is the number of passengers flown. "Once an airplane is scheduled on a particular flight, the total cost of that flight varies only slightly with the number of passengers that plane is carrying." W. Fruran, supro note 4 , at 26.

20 Reviews of these studies can be found in White, Economies of Scale and the Question of Natural Monopoly in the Airline Industry, submitted by the Public Interest Center in CAB Docket No. 31290 (rev. undated), and Woodbury, Economies of Scale in the Airline Industry: A Survey, Bureau of Pricing and DomesticAviation, CAB Docket No. 33465 (BPDA-RE-1, 1978). 
other differences in the character of the service being provided, although certain proxy variables such as average stage length ${ }^{21}$ and aircraft size are used to reflect route structure and equipment differences.

Third, the econometric results report full costs that presumably reflect the economists' concept of long-run average costs. They do not show the marginal costs of varying one or more of several conceivably relevant output measures.

Finally, the proffered econometric model equations typically "explain" only twenty to forty percent of the variance in airline operating costs. The "unexplained" variance is assumed to be due to a large number of small random factors such as unidentified differences in route structures, flight frequencies, service, equipment, and other factors.

It is unrealistic to predict industry performance or conduct when sixty to eighty percent of cost variations are poorly understood. Furthermore, the tendency (or lack thereof) for carriers to merge due to possible cost savings cannot be meaningfully examined through a cost analysis that utilizes only the available seat or ton miles measure of output. More detailed data are required to project effectively the cost consequences of the operational and strategic decisions of carriers. Only then can one begin to determine economic propensities to merge.

Service to one city pair is, from either a production or a demand point of view, a different output from service to any other city pair. There are cost differences per available seat or ton mile due to characteristics of the city pair itself, the quality of passenger services and flight equipment, and the nature of the servicewhether non-stop, direct with intermediate stops, or by connecting flights. Further, there are cost interrelationships among city pair offerings, with network effects dependent on system configurations of city pairs. ${ }^{22}$ Despite the complexity of cost relationships, the impact of changing several dimensions of service output on cost can be analyzed.

Given other factors-including aircraft type, type of service, flight frequency, and other city pairs served-cost per available seat mile tends to decrease (at a decreasing rate) as stage length increases. ${ }^{23}$ More economical cruise altitudes are possible and more

21 Stage length refers to the number of route miles between each scheduled takeoff and landing.

22 Woodbury, supra note 20 , discusses these cost factors in detail.

23 This has long been recognized. See A. Phillips, Technology and Market STRUCTURE, supra note 17, at 95, table 6-2. Regulated fares partially reflected the 
time is spent at economical cruise speeds as stage length increases. The time required for take-offs and landings is relatively invariant with respect to stage length. ${ }^{24}$ In addition, the costs of terminal equipment and ground services, while varying, although less than proportionately, with traffic density and flight frequency, do not vary greatly because of stage length alone. If average costs (including an allocation of costs that are invariant with respect to stage length and costs that vary less than proportionately with stage length) tend to fall as stage length increases, it follows that marginal costs with respect to stage length are lower than average costs.

Costs per available seat mile tend to fall as aircraft size increases. Larger aircraft types have lower unit costs, given other factors, including stage length, because gross take-off weight per seat tends to be lower as passenger capacity increases. ${ }^{25}$ Higher density seating also increases seating capacity at a rate more than proportionate to the increase in loaded aircraft weight.

Costs per available seat mile also tend to fall with flight frequency on a given city pair. This is due to the elements in total costs that vary largely with whether or not the route is served rather than with frequency itself. Ticketing and other passenger services, baggage handling, maintenance facilities, and crew stop-over facilities must be provided at terminal cities and, over some ranges, the costs associated with these activities tend to increase less than proportionately with flight frequency. While the extent of economies. with respect to flight frequency vary among city pairs, they become less pronounced as frequency increases on a particular city pair. Still, the marginal (or incremental) costs per available seat mile arising from the addition of a flight to an existing city pair is below the average costs for serving that city pair.

Other quality factors such as number of enroute stops, connecting flight service, meal and beverage service, queuing times in ticketing, baggage collection times, and safety practices affect costs. It is almost definitional that, given other factors, unit costs rise with

stage length effect on costs, with lower fares per passenger mile for longer stage length flights.

24 This is not true with respect to the particular city pairs, where differences. in congestion and weather affect takeoff and landing times.

25 This generalization is not universally true. At any point in time, a larger aircraft may have higher costs than smaller ones, even given stage length and other factors. Not all "larger" aircraft have been aerodynamically and economically welldesigned, and fitted with efficient engines for their size. Inefficient aircraft tend, however, to be rejected for commercial use, to be used in small quantities, and to be terminated from service after short periods. For some details on operating costs and carrier aircraft selection for many types up to the DC-9-10 and B-727-100, see A. Primrips, Technology and Market Structure, supta note 17, at 73-126. 
lower density seating, better food and beverage service, shorter reservation and ticketing times, and other improvements in service quality.

A very critical element in unit costs is the amount of flight equipment used. For example, if service to a set of city pairs is provided by dedicating 100 hours per week of some mix of aircraft, costs are higher than if the same flight services could be provided by ninety hours per week of the same mix of aircraft. Stated alternatively, the greater the number of available seat miles a given fleet of aircraft can be scheduled to provide, the lower the cost per seat mile. In conventional terms, this means that unit costs tend to fall as aircraft utilization rates rise. And, again, the incremental cost of higher utilization is below the average cost. ${ }^{28}$

It is clear, then, that unit costs of a carrier cannot be explained simply by the total seat miles of service it supplies. More important, the incremental costs of adding service in some output dimensions is lower than average costs even when no observable overall scale economies are present. ${ }^{27}$

Some of these influences on costs could be classified as route structure variables (for example, stage lengths and flight frequencies). Others involve capital choices (for example, the type and number of aircraft used and the terminal facilities). Still others involve quality choices. It is tempting to think that, given this complex of factors, one could adequately explain variations in cost per available seat mile. Unfortunately, even this is not the case. Differences in costs cannot be explained without describing interrelationships among the city pairs, flight frequencies, stage lengths, service qualities, and equipment used in a network of city pairs. Viewing each city pair as a separate product, the costs for one output depend not only on the volume and type of service on it, but also on the volume and type of service offered on other city pairs. That is, a carrier may experience economies or diseconomies of scope, even in the absence of scale economies. ${ }^{28}$ In particular, unit

26 The same is true of other capital inputs. The utilization rate is measured as the number of hours per day aircraft are in use in revenue service. Alternatively, utilization rates can be increased by adding more seats to a particular fleet or by flling a higher percentage of available seats. See W. Jordan, supra note 2, at 197. The rate is a proxy for the reciprocal of capital-output ratios. Unless other factor inputs increase enough to offset the effect, lower capital-output ratios (higher utilization rates) imply lower costs.

27 Economies of scale for a multiple-output firm describe the behavior of costs when all outputs are changed in the same proportion. The studies of scale economies for airlines do not, in fact, treat this precise case. See Woodbury, supra note 20 , at $20-21$.

28 See generally, e.g., Baumol, On the Proper Cost Tests for Natural Monopoly in a Multiproduct Industry, 67 AM. EcoN. Rev. 809 (1977). Economies of scope 
costs for service to, say, city pair B and $\mathbf{C}$ for a carrier will depend in part on whether the carrier also serves city pair $A$ and $B$, or $A$ and G, or $A$ and $B$ and $A$ and $C$, and the scheduling on these other city pairs.

There are at least four reasons to expect scope economies for an airline. First, some terminal, maintenance, service, and crew facilities can be shared among related city pairs, with total costs varying less than proportionately with differences in the available seat miles associated with the difference in the number of city pairs. Second, increasing the numbers of related city pairs results in possibilities for improved scheduling ${ }^{29}$ and consequently higher utilization rates for both flight and ground service equipment. Third, an enlarged mixture of flight schedules-including non-stop, direct with intermediate stops, and connecting flights-is possible as the number of served city pairs increases. Fourth, aircraft equipment choices and service quality decisions can be optimized over a broader network of city pairs. These factors are implicitly included in the term "network economies," or "route structure economies."

To the extent that scope economies (or diseconomies) exist, average and incremental costs for a given city pair shift downward (or upward) for a given type and frequency of service depending on which other city pairs are served and the volume and scheduling of those services. Carriers, of course, must consider economies of scope in their logistic planning of city pair networks, schedules, equipment, and service qualities. ${ }^{30}$ Nonetheless, published studies defining the extent and nature of scope economies are not available. Particular cases must be evaluated by the carriers on their own merit, and this is a very complicated management procedure.

The inconclusive evidence regarding airline scope economies is partly due to the regulatory constraints which impeded their ex-

exist if the cost of producing given levels of outputs of two (or more) products in a single enterprise is less than that of producing the same products in separate enterprises.

Economies of scope have found a home in the corporate planning and strategy field as well, under the vague concept of "synergy." See, e.g., Gilmore \& Brandenburg, Anatomy of Corporate Planning, in Buseness STrategx 141-55 ( $\mathrm{H}$. Ansoff ed. 1965).

29 On the importance of scheduling as a factor in overall service quality, see G. Dorman, AmLine Competition: A Theoretical and EMmirical ANalysis (1976) (Ph.D. dissertation, U. Cal., Berkeley, published in microfilm).

30 There are some other costs which must be considered. Becpuse of the substantial differentiation in the "products" involved in air travel, advertising and other types of sales promotion expenses are incurred. In addition, there are general and administrative expenses, which may not vary closely with total available seat miles, and elements of depreciation and obsolescence cost, which vary more with time than with total seat miles supplied. 
ploitation. It is improbable that the 1978 route structure configurations of the domestic airlines were anything near that which would be optimal for the individual carriers or for the collected system of carriers. The structure-and the way it was served-came about from large numbers of piece-meal, private and regulatory decisions over a period of nearly five decades. Certainly major shifts in the 1978 route structures would have made significant cost reductions possible. These shifts were ostensibly to be accomplished by deregulation.

While motives for airline merger since passage of the 1978 Act have been described as defensive moves to seek "refuge in larger size" or offensive moves for "rapid expansion," 31 underlying such moves is a desire on the part of carriers to reconfigure their routes and revise their services so as to achieve lower costs or, better, positive long term profits. The worst disadvantage a carrier could have in the face of unregulated rivalry would be an inefficient system, regardless of size. Thus, responding to the new environment, carriers attempted to adopt stage lengths, aircraft types, city pairs, flight frequencies, aircraft utilization rates, fares, classes of service, and promotional activities that, from a cost/revenue perspective, appeared sound and efficient.

\section{Demand Gharacteristics}

Efficient route configuration depends on matching cost and demand characteristics. Disaggregation of separate effects is thus needed to analyze demand, just as it was required to develop a descriptive model of costs.

For most travellers, trips between cities $A$ and $B$ are not substitutes for trips between $A$ and $C$. The trips may, of course, be complements on intermediate stop and connecting service flights. Across carriers, a trip from A to B on one carrier is to a significant degree a substitute for the same trip on another, but the two are not perfect substitutes. Furthermore, on any given route, flight schedules and frequencies, elapsed flight times, equipment types, safety records, other qualitative service dimensions, and the effects of advertising and sales promotion differentiate the carriers' outputs.

The availability of alternatives to air travel influences demand. An often ignored alternative is that of not travelling-of staying home. This may be a very poor alternative for the business traveller or the "jet setter," but may be of some consequence for holiday

31 Simowitz, supra note 18, at 44, 45. See also Williams, Eastern Spurs Air Fare Battle, N.Y. Times, June 10, 1980, at D1, D4, col. 4. 
or vacation travellers, accompanying spouses, children and parents, and lower income persons. Surface transportation by auto, rail, or ship are other alternatives. For the most part, the surface alternatives become better substitutes as stage lengths decrease and travel time differences between air and surface transportation become less pronounced. $^{32}$

The degree of monopoly power of a seller is usually assessed in terms of demand characteristics. In particular, the price elasticity and cross-price elasticities of demand are considered. The price elasticity of demand for a carrier for a given city pair, with given service type and quality, measures the percent change in revenue passenger miles ${ }^{33}$ demanded with respect to a one percent change in fare, assuming that all other factors are constant. Cross-price elasticity measures the percent change in revenue passenger miles demanded from one carrier with respect to a one percent change in the fares charged by other carriers, other alternate models of travel, or, indeed, other goods and services in general. Conventionally, monopoly power varies inversely with the (negative) price elasticity of demand as perceived by the individual seller and inversely with the (positive) cross-price elasticity of demand. That is, the better are the available substitutes from the buyer's point of view, the less is the monopoly power of a single seller. ${ }^{34}$

In a market with differentiated products, there are other very important elasticities, although both basic economic theory and antitrust principles often ignore them. The elasticities and crosselasticities with respect to qualitative aspects of the product supplied by the carriers are particularly important, and these elasticities are interdependent with price elasticities. Buyers who value certain aspects of service quality highly-flight frequency or flight time, for example-tend to be less sensitive to price differences than are those who value those same aspects less highly. Differences in the travel time among carriers due to scheduling or expedited baggage handling are more important than differences in fares for the commuter or business traveller who values time highly. Cross-price elasticity is low for that traveller-he does not shift among carriers on the basis of fare differences-while "cross-time elasticity" is

32 A survey of these and other factors affecting demand can be found in TrE Demand For Traver (R. Quandt ed. 1970). See also Eads, supta note 4. Specifications of demand models can be found in G. Douglas \& J. Muler, supra note 14, at $35-38$.

93 "Revenue passenger mile" is a measure of unit sales volume. It represents one paying passenger flown one mile. Cf. note 19 supra.

34 See, e.g., F. Scherer, supra note 6 , at $385-403$ for a discussion of the relationship between product differentiation and market structure. 
high-he will shift among carriers because of travel time differences. ${ }^{35}$

The several perceived elasticities of the carriers are also affected by the ease with which others may enter (or duplicate) the service. If it is felt that an increase in a fare on a city pair will cause others to enter, offering a substitute service with a combination of price and service quality that will attract buyers, the price elasticity appears high to the carrier contemplating the higher fare. Little monopoly power over price exists. If it is felt that a failure to offer high quality service on a city pair will cause others to enter, little monopoly power over service quality exists. Entry possibilities constrain carriers from raising prices and/or lowering service quality. ${ }^{36}$ This does not mean that quality differences will not exist. It does mean that possible gains deriving from monopoly power-price differences greater than those needed to cover the cost differences associated with quality differences-are unlikely to emerge where quality changes are easily available to other suppliers.

An individual carrier will, of course, be influenced in its perceptions of demand by what it regards as the likely price, quality, and advertising responses of actual and potential rivals. The higher the cross-elasticities, the more likely it is that competitive responses will be made by those rivals. ${ }^{37}$

The effects of changes in price, quality, or advertising are not necessarily symmetrical, or identical, among the carriers. What little general analysis is possible on this point suggests that "the impact of a firm's price changes on the share of the market enjoyed by its rivals is correlated with the proportion of the market originally controlled by the firm." 38 Although such analysis re-

35 For an application of consumer choice and consumer benefits arising from travel time differences, see Carlton, Landes \& Posner, Benefits and Costs of Airline Mergers, 11 BELL J. ECON. 65 (1980); Eads, supra note 4.

36 See notes 46-53 infra \& accompanying text.

37 It is not necessary that a change in quality, for example, be responded to by a change in quality by competitors. The latter might respond by changing fares instead of, or along with, quality. Either situation implies inter-carrier rivalry.

38 L. Schwartz \& J. Flynn, Anttrrust and Regulatory Alternatives 917 (1977) (citing Phillips, Price Discrimination and the Large Firm: Hobson's Choice in the Pectin Industry, 43 V. L. Rev. 685 (1957)). Ignoring for the moment the peculiarities of the airline industry, consider two rival sellers with one having 80 percent and the other having 20 percent of a clearly defined market for differentiated products. If each has a price elasticity of -2.0 , a price reduction of 10 percent by the larger would, with no response by the other, increase its sales by $.20 \times .80=.16$, or from 80 to 96 percent of the market. The smaller firm's sales would fall from 20 to 4 percent. If, on the other hand, the smaller firm lowered price by 10 percent and the larger firm did not respond, its share would rise by $.20 \times .20=.04$, or to only 24 percent of the market. The larger firm's share would fall to 76 percent. Similar results might arise from the use of quality variations rather than price as a competitive tool. 
quires critical assumptions about the demand elasticities of the firms, the possibility that the larger firm can, through its initial impact on others, more easily "police," exclude, or act predatorily with respect to smaller firms must be recognized. Equivalent responses by the smaller firms may not offset the initial actions by the larger firm. In such circumstances, a smaller firm may be reluctant to compete aggressively with a larger one. When size distributions are more equal, the asymmetries tend to disappear.

The complexity of the airline product defies mechanical application of this analysis. For airlines, asymmetries in cross-demand relations are undoubtedly extremely complicated. Carrier size, in terms of aggregate seat miles supplied, may not be very important. Rather, the posture of individual carriers in certain city pairs, sets of city pairs, types of service, and service frequencies have to be considered. A carrier offering in the aggregate a relatively small total number of seat miles per year may, because of factors such as frequency, "on-line feed," 39 and customer recognition in the particular service, have an advantage over much larger rivals. Moreover, because of differences in cost factors discussed above, the smaller carrier could have the lowest marginal costs for certain types of service.

Minimizing costs is not always the key to successful operations, however. There are qualitative aspects of air service for which customers are willing to pay and which sometimes cause costs per available seat mile to increase. The most important of these quality factors is time spent in travel. Increases in flight frequency is the primary way in which the carriers can reduce the time required for customers to move from point to point. Higher frequencies usually mean higher average costs, however. ${ }^{40}$

For example, an aircraft with 500 seats can service a stage length of 100 miles by one round trip per day-or 100,000 seat miles-at far lower cost per seat mile than would a few 25-seat planes making twenty round trips throughout the day. The

39 "On-line feed" results from the coordinated scheduling of arriving and departing flights from "hub," or significant interchange, airports. The objective of the scheduling is to maximize the extent to which one carrier's own flights can "feed" one another, reducing the amount of passenger revenues lost to other carriers. On-line feed has value to passengers also, because it ordinarily reduces the time required for making connecting flights. See R. Joedicke, Hub and Spokes Scheduling, or Reinventing the Wheel: A Prime Justification for Airline Mergers (August 22, 1978) (Industry Comment, Lehman Brothers Kuhn Loeb).

40 Higher frequency also generally results in lower load factors. The load factor is the ratio of revenue passenger miles to available seat miles-or the percentage of seats actually sold. Load factors, among other things, are directly related to profitability. 
greater frequency of the latter, however, would be positively valued by consumers. Higher frequencies reduce passengers' time coststhe costs of having to match the time of other activities with those of the air schedule. Given equal fares (and no strong consumer preferences for larger aircraft), more revenue passenger miles would be demanded with the more frequent service. The more frequent service is, in a real sense, a different product from both the cost and demand points of view. In fact, higher fares per mile are often charged by the carrier with more frequent service, especially on short trips. Equipment choice and scheduling decisions must consider both costs and revenue and, on some routes and for some classes of service, "economies of specialization" may arise for small carriers with a relatively low aggregate supply of seat miles. Commuter airlines are an illustration of this phenomenon. ${ }^{41}$

The demand for a particular carrier is affected by other similar qualitative factors. Passengers generally prefer non-stop service for the city pair involved in their travels. When non-stop service is unavailable, the order of preference, based on time, is for direct flights (with no change of planes and short layover times); multiplane, single-carrier trips (with on-time service and the minimum layover necessary to connect); multi-carrier trips (with on-time service and minimum layover necessary to connect). Carriers attempt to arrange schedules to achieve the best mix of costs and revenues that result from these demand preferences. In particular, they look for "on-line feed" and "hubbing" in order to keep costs down and keep passengers on the flights of the carrier originating the passengers' trip. ${ }^{42}$

Facilitating carrier response to these demand characteristics is an important private, and sometimes social, reason for permitting mergers. Regulation had for years masked inefficient service, and had discouraged more competitive moves by the efficient carriers. Airlines suffered from a lack of incentives to implement efficient

41 See, e.g., Nontrunk Earnings Outpoint Costs, 112 AvLATION WЕЕK 227 (1980); Survey, U.S. Commuter Airlines, 17 Am Transp. Worrd 78 (1980); U.S. Locals Sustain Outstanding Traffic, Financial Performance, 17 ATR Transp. WORLD 61 (1980).

42 See Carlton, Landes \& Posner, supra note 35, which analyzes the increased value to passengers resulting from the merger of North Central Airlines with Southern Airways. The authors conclude, inter alia, that the consumer preference for single carrier service was so significant that such service "does not merely divert traffic from multiple carriers, ... it also creates new traffic." Id. 74 (footnote omitted). For some interesting theory and an empirical test of the importance of frequency, see Spiller, The Differential Impact of Airline Regulation on Individual Firms, Discussion Paper No. 76, Center for the Study of Organizational Innovation, U. of Pa. (July 1980). See also Pustay, Airline Competition and Network Effects, 12 Transp. L.J. 63 (1980) (discussing feeder effects and the resulting ability to compete for passengers). 
changes in route structures. In the face of deregulation, the carriers were forced to make moves perceived as efficient, armed with little precedent and with only conjectural knowledge of what other carriers were doing in the same regard. The "scrambling" for routes by the carriers when route certification restrictions were eased in 1978-1979 43 was obviously a means of "buying insurance." 44 Even if particular route authorizations were not exercised, the freedom to move quickly in altering route structures was a nearly costless way to obtain a wide choice set for the carriers. It is unlikely, however, that the sum of these individual, intracarrier decisions would attain the cost savings that would ensue were efficiencyinduced mergers allowed. To the contrary, such decisionmaking will result in the supply of seat miles or service planned on particular segments grossly exceeding the demand..$^{45}$

\section{Carrier Conduct and the Market}

\section{A. Entry Barriers and Potential Competition}

Profit-maximizing strategies for the individual carrier, it is clear, are complex. The airline industry is not one for which the concept of equating the marginal cost to the marginal revenue from a single, homogeneous product is especially pertinent. The "marginal" considerations extend in many dimensions. Costs, fares, advertising, equipment choices, route scheduling, and service qualities are all interrelated. Even in pure theory, it is enormously difficult

43 Civil Aeronautics Board authority over route certification officially dissolves on December 31, 1981. Airline Deregulation Act of 1978, 49 U.S.C. $\$ 1551$ (a)(1) (Supp. II 1978).

4 See, e.g., Eastern Air Lines, Inc., 1979 Annual Report 2 (1980):

Eastern continued to strengthen its route system adding eight new cities during 1979 while suspending service in eight cities with little or no growth potential. One key to our route strategy is the expansion of service from our Atlanta hub....

While Eastern has improved its financial and operational position in recent years, the airline continues to face further challenges. The Airline Deregulation Act of 1978 has produced new competition for Eastern on routes that account for 40 percent of our available seat miles.

45 Even during the regulated period of operations, Fruhan, among others, noted the tendency of competing carriers to attempt to achieve market dominance by scheduling more flights-flight frequency being one major area in which the carriers retained flexibility. He argued that this rivalry was ultimately destructive. W. FrUtan, supra note 4, at 124-52. Although his conclusions concerning the direct relationship between scheduling and profitability have been challenged, see White, supra note 20, at 30-32, the problem of overexpansion is real. Braniff Airlines, for example, cited overextended service and underutilized aircraft as primary reasons for its precarious financial situation. See McInnis, supra note 8. 
to establish optimal prices when there are cost interdependencies (economics of scope) and demand interdependencies for the several products of a multi-product firm. ${ }^{48}$ A change in the price or quality of any one product affects the costs and revenues relating not only to that product but to all of the firm's other activities as well.

The significance of entry as a factor limiting the market power of an airline has to be considered in this context. On any particular city pair, the carrier's total output comprises a combination of fares and service qualities. There are costs that can be measured in terms of the incremental outlays involved in providing the service or in terms of the alternative net revenues that might be obtained if the same resources were used to offer a different service on the same or a different city pair. This assumes that the output mix of a carrier-type of service, equipment allocation, city pairs served-can be shifted relatively easily to a putatively preferable combination. ${ }^{47}$

While this freedom in the choice of service allows any one carrier a great deal of discretion in seeking its own best mix, it also means that other carriers have similar discretion. Thus, each carrier on each city pair faces a combined "limit price" and "limit service quality" such that, if its price were any higher or its service quality any lower, another carrier would find it attractive to begin or to increase service on that city pair. ${ }^{48}$ When the price-quality limits are violated and entry responses by other carriers occur, the entire cost-revenue configurations of both the existing and the entering carriers are affected. Because each carrier is typically a multicity pair operator, the interdependence among the carriers is extremely complex and leads to keen attention by any one carrier to the possible reactions of others to its mix of fares and services. The resulting limit on fares and service quality, combined with the great mobility of carrier capital, are severe constraints on the exercise of monopoly power-so long as the carriers behave independently and without collusion.

The effect of potential entry by others on carriers presently serving certain city pairs does not depend critically on the number of possible entrants. An existing carrier perceiving only one pos-

46 For an indication of the problem, see Phillips, Ramsey Pricing and Sustainability with Interdependent Demands, in Regulated INDUSTrIEs AND PuBLIC ENTERPRISE (B. Mitchell \& P. Kleindorfer eds. 1980).

47 This assumption is generally accepted. The best possible proof of the ease of shifting is the frequency of just such changes shown in the OFFICIAI ArruINE Gumes. The North American Edition of the Gume has shown far more scheduling and route changes since the advent of deregulation.

48 For a discussion of "limit pricing," see F. Scheren, supra note 6, at 232-52. 
sible entrant on each of its routes may be as effectively constrained as if there were many. ${ }^{49}$ It can be argued, in fact, that large numbers of potential entrants reduce the probability that any one will enter.00 Each may be deterred by the probability that its entry will coincide with that of another when the number of potential entrants is large. In any case, whether there are many or only one potential newcomer to a service, the limits placed on price and quality are those of the "best" potential newcomer. Ease of entry brings a price-quality configuration by the existing carriers that approximates their perception of what is just necessary to prevent any other carrier from entering.

It must be recognized, nonetheless, that the effect of potential entry could be undermined by anticipations of defensive and strategic reactions of existing carriers. An aggressive carrier, with efficient operations and low marginal costs for changing its frequencies, schedules, and fares, may indeed possess advantages over "outside" carriers that weaken the entry incentives of the latter. In the short term, an existing carrier can, for example, lower fares or increase flight frequency on the city pairs on which entry occurs or on which entry is probable. A strategy of increasing flight frequencies on the threatened routes while decreasing frequencies on other, unthreatened routes could be employed. This form of "flight frequency" discrimination can be used without fare changes; its predatory potential may not be recognized.

Entry barriers may also arise for reasons having little to do with the structure of the carriers. These include imperfections in capital markets and equipment availability. Were a really new firm-an unknown XYZ Corporation-to be founded in the expectation of entering the routes of established carriers, it probably would find financing difficult. The venture would be large and risky. Lenders would find preferable uses for their funds.51 This would be less true, however, if a well-established firm outside the air transportation industry elected to enter. It is even less true for established carriers that enter new city pairs by altering their route structures. And it is from these that the primary potential entrants are found.

49 If a single entering firm has the potential of capturing a significant portion of sales, while each of several entrants would take only a small portion, the single firm may have a greater constraining effect. F. ScFIERER, supra note 6, at 248-51.

50 See Sherman \& Willett, Potential Entrants Discourage Entry, 75 J. Por. EcoN. 400 (1967).

51 See Manheim, Trunk Carrier Size and the Availability of Capital, Office of Economic Analysis, Civil Aeronautics Board (1978). 
Ability to obtain equipment also affects ease of entry. New flight equipment often takes several years from order to delivery. To the extent that entry requires new equipment, this time lag reduces the competitive effect of entry. But there is an active market for used aircraft, with acquisition either by lease or by purchase. Used aircraft are often fairly good substitutes for new aircraft, particularly from the cost side, because their market prices reflect to a degree their performance and cost attributes relative to new equipment. Still, the longer the order queue for new aircraft, the more likely it is that the old equipment prices include scarcity rents. The queue is not an insurmountable obstacle, in any case, because carriers can and do buy and sell places in manufacturers' order positions.

Another important entry barrier sometimes arises because of limits on airport access. Physical facilities-gate space, for exampleand takeoff and landing time "slots" may not be available. Current practices usually involve a quasi-voluntary rationing scheme devised by the carriers serving an airport and airport managers to allocate scarce ground and air space, with provisions for new applicants. Such shortages would not justify an otherwise objectionable merger; neither would the restrictions on airport access bring into question a merger that was otherwise unobjectionable. Limits on airport access, in fact, probably encourage mergers to a minor extent because mergers reduce the need for duplicate ticketing and baggage handling facilities and the requirement for separate gates.62

The entry barriers raised by inherent weaknesses in capital markets and by the difficulties in obtaining new flight equipmentcoupled with the strategic reactions of existing carriers to cut fares, increase frequency of service, or engage in promotional wars-can undermine the ability of potential entrants to limit the market power of their already-entrenched rivals. It follows that policies aimed at promoting the efficiency of existing carriers-because they are the most probable entrants into one another's route structures -increase the effectiveness of the entry constraint throughout the entire system. This is true even if gaining the efficiencies requires some reduction in the number of carriers. While this hardly argues for having only one or a few carriers in the nation, it does

52 See Civil Agronautics Board, Proceedings, Merger Policy and thre Condmions of ENTmy In the Am Transportation Industry 5-10 (Nov, 15, 1978) (testimony of John R. Haring, Jr. and Richard A. Ippolito) [hereinafter cited as CAB Prockeedings]. For a broader perspective, see Arrport Economac PlanNing (G. Howard ed. 1974). Haring and Ippolito point to the presence of a competitive rental market in airport space, particularly at major hub cities. CAB Procesonngs, supra, at 10. 
suggest that having a set of carriers with strengths from hubbing, on-line feed, and low incremental costs for various service extensions would increase overall competition in the industry by enhancing system-wide entry possibilities. ${ }^{53}$

\section{B. A Digression on Market Definition}

No attempt has been made to "define" a relevant market. Despite the fact that market definition is, from the view of antitrust policy, a "necessary predicate" to the determination of the competitive consequences of a merger, ${ }^{\sigma 4}$ there is a growing view in economics and in the law that the shares of particular firms in the defined market are an inadequate basis on which one can properly conclude whether a merger may tend substantially to lessen competition. $^{53}$ Even when a market is easily defined, the evaluation of the monopoly power of firms within it requires an investigation of the nature of the competitive process and of the constraints that may exist on the use of market power due to factors not included in crude measures of market concentration.

It is unrealistic to assess monopoly power or the effects of a merger solely by number of carriers on a given city pair or set of city pairs. ${ }^{50}$ The key issue is entry. If a market (or markets) must be defined for legal reasons, it has to be recognized that it is crosssupply elasticity (that is, ease of entry) that should define the market. When a particular city pair or set of pairs can, on the basis of incremental costs, be entered easily by carriers serving other routes, the relevant market, defined most narrowly, consists of all

53 It bears repeating that an efficient integrated airline structure is as yet unknown in the United States. The optimum situation may require fewer trunk carriers that are national in scope, serviced by a greater number of leaner, more regionalized carriers. Cf. CAB Procendngs, supra note 52, at 9-10 (Nov. 6, 1978) (testimony of Thomas E. Keeler).

54 United States v. E.I. Du Pont de Nemours \& Co., 353 U.S. 586, 593 (1957).

55 Even in Brown Shoe Co. v. United States, 370 U.S. 294 (1962), the Supreme Court viewed concentration ratios as the "primary index of market power," but stipulated that "only a further examination of the particular market-its structure, history, and probable future-can provide the appropriate setting for judging the probable anticompetitive effects of a merger." Id. 322 n.38. In United States v. Marine Bancorporation, 418 U.S. 602 (1974), the Court noted that concentration ratios "can be unreliable estimates of actual market behavior." Id. 631 (citing United States v. General Dynamics Corp., 415 U.S. 486, 494-504 (1974)). While a number of economists continue to believe that concentration ratios are good indicators of the degree of competition in a market, there are growing theoretical and empirical grounds for the contrary proposition. See, e.g., Dasgupta \& Stiglitz, Uncertainty, Industrial Structure, and the Speed of R\&D, 11 BErL J. EcoN. 1 (1980).

so The CAB appears to agree. See Texas International-National Acquisition Case, 2 Av. L. REP. (CCH) \22,327, at 14,156 (1979). 
of the carriers capable of efficient entry. The computation of precise shares of the market is, of course, impossible when the crosssupply elasticity is the most important consideration.

With markets defined in terms of cross-supply relationships, intersections among competitive sets of carriers are apparent. The concept of $a$ market disappears. "Markets," as seen by the rival carriers, are indefinite and amorphous, with the relevant sets of competitors varying within and among city pairs.

\section{Mergers Among Air Carriers and Public Policy}

Translating the cost, demand and entry conditions of the domestic airline industry into sensible public policy requires a "divorcement of thinking" from the established antitrust mold. Airline mergers are nearly inevitable in the deregulated environment. Furthermore, some mergers will be motivated by and will probably produce efficiencies otherwise unattainable. The question is whether policy will recognize this during the early years of deregulation and promote an orderly transition to an efficient structure or whether, as the letter of the 1978 Act can be read to require, policy will follow antitrust guidelines. ${ }^{57}$

The conclusion that more mergers are inevitable follows for several reasons. First, in their initial moves for market position in the unregulated markets, some of the carriers have added routes and service classes on the basis of short run, incremental cost and demand characteristics. While this may make some sense from the individual carrier's point of view-incremental revenue for that carrier may exceed incremental costs-other carriers will react similarly to provide services on an incremental revenue and incremental cost basis. The consequence is that many carriers begin to operate at a loss. This obviously cannot continue in the long run. If it is assumed (unrealistically) that conspiracies to fix fares and routes will not be attempted or (realistically) that these conspiracies will not be effective, some carriers are likely to fail for

57 Simowitz, supra note 18, arguing perhaps too strongly that the $\mathrm{CAB}$ has been more lenient than the courts would be under $\$ 7$ tests, correctly notes that "one should not assume that the recent surge of mergers has spent itself." Id. 67. He does not address, however, the question of what new policies the CAB might pursue prior to handing merger authority to the Department of Justice in 1983. Airline Deregulation Act of 1978, 49 U.S.C. $\$ 1551$ (Supp. II 1978). Brodley, supra note 18, reviews airline merger cases through 1980 and finds $\mathrm{CAB}$ decisions generally in accord with decisions made under the antitrust laws. Brodley rejects the use of efficiency criteria in evaluating mergers, and finds market share statistics, as used in antitust cases, useful in judging the probable anticompetitive effects of airline mergers. 
this reason alone.58 Long run profits, not short run contributions to overhead, are needed for survival. To the extent that mergers yield more efficient operations-or shield carriers from such ruinous rivalry-mergers will be encouraged by the threats to survival.

Second, anticipating overall growth in passenger demand and expansions of routes, the individual carriers have placed and are placing orders for new flight equipment. It is not an unreasonable assumption that the sum of the planned expansions by the individual carriers far exceeds the growth that will occur in passenger demand. As new equipment is delivered, excess capacity may arise, making it more difficult to curb the continuation of unilateral route, fare and service class decisions that, for the entire industry, spell negative profits. Negative profits threaten survival and encourage mergers.

Third, the cyclical and generally slow growth of the economy makes it likely that whatever excess capacity exists will be accentuated by periods in which increases in passenger demand fail to materialize or, as in 1980, demand actually falls for most of the carriers. ${ }^{59}$ Again, negative profits and negative cash flows threaten solvency. This situation also means that the market for used aircraft will be lower than that anticipated when new replacement aircraft were ordered.

Finally, the existing route structures and accompanying services still reflect those that the $\mathrm{CAB}$ and predecessor agencies erected when the carriers were protected from competitive pressures. Rearranging route structures to achieve greater efficiency is much less costly-privately as well as socially-when done together by more than one carrier. Mergers are thus the least costly way of altering the overall structure of routes and services in the United States.

To avoid the inevitable forced merger of a number of failing carriers-and, in fact, to stymie consequent political pressures to re-regulate the industry-a policy favoring mergers that allows the development of more rational routes and services should be encouraged. This will, of course, mean a smaller number of carriers but, given entry conditions and scope economies, there is no reason to associate a smaller number of larger and more efficient carriers with a substantial diminution in competition. Put another way, the

58 In fact, collusive agreements are difficult to reach and more difficult to enforce in such complex circumstances. This is true even when the number of parties to the agreement is small. For a discussion of this, see O. WhLLIAMSON, MARKETS AND HERARCHIES: ANALYSIS AND ANITTRUST IMPLICATIONS ch. 12 (1975).

59 Consumer statistics can be found in UnITED States Crvil Aenonautics Board, Air Gafruer Trafric Statistics. The reports, published monthly, contain statistics for each month, and for the twelve months ending with that month. 
kind of competition among the larger number of then existing carriers envisioned by the architects of deregulation is probably impossible to achieve. The prior regulations kept that structure intact. Deregulation and competition will cause the structure to change.

This must not be interpreted to mean that all airline mergers are necessarily good because they are induced by rivalry, competitive pressures, and low level earnings. The critical point is rather that one should not conclude that a merger has the proscribed anticompetitive effects simply because the number of carriers is reduced. A merger between two carriers that produces neither demonstrable cost nor quality advantages and that, because of size or other unique characteristics, makes entry substantially more difficult, should be disallowed. As a general principle, the larger the carriers in the aggregate, the higher the occupancy of the carriers on relevant route segments, and the greater their similarity in route structures, the more likely it is that a merger would lessen competition without any compensating benefits. The relevant route segments, moreover, should include those that, with scale and scope economies considered, might logically and reasonably be added to the system of either or both of the carriers.

There is a vast difference, however, between the anticompetitive case just suggested and that in which the merger may provide cost reductions and service improvements. If the improvements are due solely to the elimination of poor management on the part of one of the parties, there would again be little justification for permitting a merger. On the contrary, if the merger allows cost reductions and service improvements that cannot be obtained by either of the carriers acting unilaterally, and if there is no less anticompetitive alternative available to accomplish the same purpose, the merger may be justified. The "public interest" should recognize that at some point one or both of the carriers will be eliminated from the market absent the efficiency inducing merger. Other, more efficient, carriers will take their places.

In all of this, the new competitive environment-especially the freedom of one carrier to enter any route segments of other carriers where some profits or contributions to overhead can be realized-is a very important consideration. Monopoly power can sometimes be reduced (or not increased) when firms combine. If cost efficiencies or service improvements due to scope economies or other aspects of input and output combinations result from a merger, the relevant incremental costs for current services and the 
costs for extensions of service may be reduced. When this occurs, the merged firm is a stronger potential entrant. ${ }^{60}$ Substituting one efficient, competitive firm for two firms, neither of which efficiently serves its own market or can effectively enter other market areas, is a move toward the competition that deregulation should be designed to provide. In addition, the combined firm may be in position to weather possible strategic responses by rivals that the individual firms could not do.

Entry conditions are obviously the most important factor to assess when the number of carriers is small. That a less efficient rival, or a rival with poor management, is eliminated as a potential entrant or actual competitor should not bear weight here. Merger policy should foster efficiency and competition and not protect particular carriers in the interest of preserving large numbers alone. In fact, an inefficient firm, viewed either as a potential entrant or in terms of its effectiveness as an actual competitor, is of de minimis importance to competition in any case.

\section{Gonclusion}

The analysis proffered here leads to the conclusion that airline merger applications should be carefully but liberally treated in the immediate future. Coming full circle, it raises the question of what the dynamic, time-related patterns of structure, conduct and performance are likely to be. Consider this scenario:

Suppose that, for whatever reasons, ${ }^{61}$ mergers among any of the present trunk carriers are generally disallowed wherever some ostensibly anticompetitive consequences arise because of "increased concentration" on some route segments, wherever an existing firm may be threatened by the merger, and without regard to demonstrable cost savings or service improvements that the merger may produce. Assume that present route structures, resulting as they have from an historical sequence of $\mathrm{CAB}$ certification and merger decisions, are not the most efficient set. Suppose that route structure adjustments without mergers sometimes have higher incremental costs than do route adjustments with mergers. Add, if appropriate, that the present size, network characteristics, and possible responses to entry of some carriers tend to deter entry on

60 Potential competition is also enhanced when the merged firm services both ends of a particular city pair, where previously only one of the merging firms had operated at each end.

01 One possible reason is the transfer of merger oversight to the Department of Justice, an agency without expertise in the air transportation industry. 
some routes. Now add-quite realistically-that the demand for air travel is cyclical in nature and that fleet addition decisions already made will result in delivery of a good deal of new capacity in the years ahead.

The result-sometime in the near future if not today-is clear. Excess capacity-low load factors, low utilization rates, low profits, and strong rivalry among carriers-appears. Some carriers-denied the opportunity to obtain more efficient network structures and to reach sizes and operating strengths adequate to prevent or deter incursions into their routes by other, perhaps larger, firms-will fail. Merger applications will be made in a crisis-like environment, with the failing firm defense often claimed. Even then, efficient structures may not emerge because the crisis-bred mergers may be based more on the creation of long-run monopoly power than on efficiency gains. The nation may be left with a really small number of large, quasi-monopolistic and not necessarily efficient carriers.

An alternative scenario is possible. It requires judicial and administrative disregard of the time-worn reliance on market concentration as determinative of future conduct or performance. It assumes, nonetheless, all the other conditions of the first scenario.

A proper approach to proposed mergers would begin with a demonstration of cost savings and service improvements from the consolidation of route structures and facilities. As prima facie evidence of cost savings, the parties could be required to show convincingly that the existing routes of both carriers, with roughly the existing flight frequencies among city pairs and existing equipment, could be maintained at lower costs, or with less equipment, fewer personnel, and better service to passengers. ${ }^{62}$ This, of course, would not preclude some changes in schedules to permit improved utilization, better on-line feed, and changes in non-stop, direct, and connecting flights. Because of the need for restructuring, and the ease of entry, virtually no attention would be given to the number of carriers actually operating on a particular route segment.

Evidence of cost savings could be countered with a showing of substantial anticompetitive effects. This again would require more than a simple showing of elimination of a potential entrant. Rather, the analysis must consider the complex cross-demand and supply relationships discussed above.

The result of the second approach is better. Fewer crisis-bred mergers will result. Greater efficiency will be obtained. The competitive threats inherent from anticompetitive behavior induced by

62 This is not an fmpossible task. See Carlton, Landes \& Posner, supra note 35. 
excess capacity will be less severe. And, as an important side effect, current decisions concerning future equipment will be made in the light of efficient rather than second-best route structures. Delaying efficiency-creating mergers until it is better known what the effects of deregulation will be increases the probability that the effects will be recorded as disastrous.

It is possible to have a deregulated, competitive airline industry in the United States. Despite the absence of scale economies, however, all-or even most-of the present carriers will not be able to survive in that competitive state. Mergers are but a necessary phenomenon in the process of moving from regulation to deregulation, and from an inefficient to an efficient air transportation system. 